\title{
Defined Observation Result Confidentiality Code
}

National Cancer Institute

\section{Source}

National Cancer Institute. Defined Observation Result Confidentiality Code. NCI

Thesaurus. Code $C 93779$.

A coded value specifying the deg ree of privacy applicable for the observation result. 